\title{
Design of natural-rubber panel railroad crossing using finite element method
}

\author{
Aunna Sukhom ${ }^{1}$, Ittipol Jangchud ${ }^{2}$, Monsak Pimsarn ${ }^{3}$, Jarruwat Charoensuk ${ }^{3}$, and Veerachai Treeporncharoen ${ }^{4}$ \\ ${ }^{1}$ Automotive Engineering, International College, King Mongkut's Institute of Technology Ladkrabang, Chalongkrung, Bangkok, \\ Thailand \\ ${ }^{2}$ Department of Chemistry,Faculty of Science, King Mongkut's Institute of Technology Ladkrabang, Bangkok, Thailand \\ ${ }^{3}$ Mechanical Engineering Department, Faculty of Engineering, King Mongkut's Institute of Technology Ladkrabang, Bangkok, Thailand \\ ${ }^{4}$ Extensive Research Polymers Co. Ltd., 26 Moo 4 Tamboon Nonghong, Panthong, Chonburi, Thailand
}

\begin{abstract}
.
Thailand has a railway system that is available throughout the country, so there are several railroad crossings. These crossings are generally made of concrete or logs with multiple constraints. There are some disadvantages of concrete railroad crossing, such as, crack, noise during car passing over. To overcome these disadvantages, the softer materials should be used instead. Therefore, this research proposes the natural rubber, widely grown throughout Thailand, panel railroad crossing. However, the natural rubber alone is not enough to withstand the harsh condition. Thus, it is necessary to have some addition ingredients that will enhance the natural rubber properties. The material used in this research is a rubber compound between Chloroprene Rubber (CR) 75\% and Natural rubber (NR) 25\% blend with additives such as carbon black (CB), magnesium oxide $(\mathrm{MgO})$ and sulfur $(\mathrm{S} 8)$. The objectives of this article were to analyze the deformation of the natural rubber panel railroad crossing and to evaluate its safety factor, defined as the ratio of strain at break and the maximum equivalent strain, using finite element method. In the analysis, the applied loading of the model was obtained from the State Railway of Thailand. The analyzed results reveal that the deflection of rubber panels passes the standard from State Railway of Thailand. Safety factor of external rubber panel is 27.03 and for internal rubber panels are 9.12 and 15.29. The metal pads had elastically deformed and concrete railroad sleeper deformation was very small.
\end{abstract}

\section{Introduction}

Thailand in one of the countries that has the highest production capacity of rubber in the world. Although Thailand's rubber exports around $87 \%$, export revenues are about 193,067 million Baht per year, but domestic processing about $13.4 \%$ of rubber can generate about 230,000 million Baht annually. Thailand is experiencing several problems with natural rubber, such as the volatility of raw rubber prices, the problem of natural rubber production that does not meet the market demand, the problem of the quality of raw rubber, the problems of the rubber market and competitors from the other countries. Therefore, Thailand focuses on the development of rubber processing industry in the country to increase the amount of rubber before selling, it will increase revenue for farmers. At present, the railroad industry is growing in the future due to investment in the development of the rail system in Thailand. The BTS network in Bangkok and the government's "nationwide double-track railway project ". According to the State Railway of Thailand. Currently, Thailand has a railroad track of approximately 4,346 kilometers. There are more than 2,500 railroad crossings across the country. Generally, these crossings are made of concrete or logs. The disadvantages of using these materials are lifetime limit, cracking problem, damaged concrete cushions due to impact with crossing panels. Additionally, there are problems in rainwater drainage and in noise generation during the cars passing through. The vehicle passing through must slow down, resulting in traffic problems at the intersection. Concrete and logs are brittle material that are not resistant to repetitive force. Breaking or cracking causes accidents and wastes the repair budget. The problem can be solved by finding materials that can withstand repeated repetitive forces. Rubber is a good choice. The advantages of using rubber to produce rubber crossing panels such as rubber are soft material, no rupture, good for vibration and silence while the car runs through. There are also promoting the use of rubber in Thailand, design and production of prototypes that are feasible to commercialize by Thai companies. The design of the workpiece should be appropriate for the actual use, including the finite element method for deformation and the estimated lifetime of the rubber panels. If the project is successful, it will be a key 
variable for the country and the government. As a result, the country's economic, social, agricultural and security development has increased. The Institute hopes that the project will be able to respond positively and significantly to the government.

\section{Methodology}

\subsection{Material properties}

Initially, the analysis needed to determine the material properties. The material used is the compound rubber that has been researched and develop a formula for support the impact between the rails and concrete pillars. The chemical composition is given in Table 1. The mechanical properties of the rubber are derived from the tensile test data, as shown in Fig 1. Table 2 shows the derived mechanical properties. Moreover, the rubber hyperelastic properties were also considered in this paper and Yeoh's model was employed.

Table 1. Chemical composition of rubber. [1]

\begin{tabular}{|c|c|c|c|c|}
\hline Ingredient & $\begin{array}{c}\mathrm{CR} / \mathrm{NR} \\
\text { ratio }\end{array}$ & $\begin{array}{c}\text { carbon } \\
\text { black(CB) }\end{array}$ & $\begin{array}{c}\text { magnesium } \\
\text { oxide }(\mathrm{MgO})\end{array}$ & $\begin{array}{c}\text { sulfur } \\
\left(\mathrm{S}_{8}\right)\end{array}$ \\
\hline composition & $75 / 25$ & $60 \mathrm{phr}$ & $1 \mathrm{phr}$ & $1 \mathrm{phr}$ \\
\hline
\end{tabular}

Table 2. Mechanical properties of rubber. [1]

\begin{tabular}{|c|c|c|c|}
\hline $\begin{array}{c}\text { Tensile } \\
\text { Strength } \\
\text { (MPa) }\end{array}$ & $\begin{array}{c}\text { \%Elongation } \\
\text { at break }\end{array}$ & $\begin{array}{c}\text { Modulus at } \\
\mathbf{1 0 0} \%\end{array}$ & $\begin{array}{c}\text { Poisson's } \\
\text { ratio }\end{array}$ \\
\hline 19.718 & 513.916 & 3.8605 & 0.49 \\
\hline
\end{tabular}

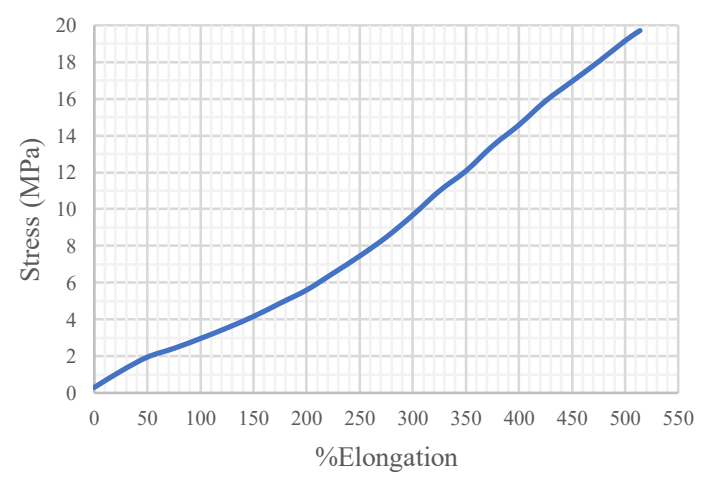

Fig. 1. Tensile test result of rubber.

Yeoh $3^{\text {rd }}$ order model is the most suitable model that can predict behaviour of compound rubber and its constitutive model is given in equation 1 .

$W=C_{10}\left(I_{1}-3\right)+C_{20}\left(I_{1}-3\right)^{2}+C_{30}\left(I_{1}-3\right)^{3}$

From curve fitting process using ANSYS, the Yeoh $3^{\text {rd }}$ order model parameters are $\mathrm{C}_{10}=82.595 \times 10^{5} \mathrm{~Pa}$, $\mathrm{C}_{20}=15.303 \times 10^{4} \mathrm{~Pa}$ and $\mathrm{C}_{30}=-54.453 \mathrm{~Pa}$
Table 3. Mechanical properties of used material. [2,3]

\begin{tabular}{|c|c|c|c|c|}
\hline Material & $\begin{array}{c}\text { Ultimate } \\
\text { Tensile } \\
\text { Strength } \\
\text { (MPa) }\end{array}$ & $\begin{array}{c}\text { Yield } \\
\text { Strength } \\
\text { (MPa) }\end{array}$ & $\begin{array}{c}\text { Young's } \\
\text { modulus } \\
\text { (MPa) }\end{array}$ & $\begin{array}{c}\text { Poisson's } \\
\text { ratio }\end{array}$ \\
\hline $\begin{array}{c}\text { Structural } \\
\text { Steel }\end{array}$ & 460 & 250 & 200,000 & 0.3 \\
\hline Concrete & 5 & 0 & 40,000 & 0.18 \\
\hline
\end{tabular}

\subsection{Loading and Boundary condition}

Analysis of 3D problems by finite element method was done using ANSYS workbench program. The load is coming from vehicle wheel. The load value is 22.5 $\mathrm{kN}[4]$, which is the standard value set by the State Railway of Thailand calculate form real load $15 \mathrm{kN}$ multiple with 1.5 safety factor. Press the load into 3 areas of the model to evaluate deformation. The components of simulation model shown in figure 2. Loading apply area and fixed condition shown in figure 34 and 5.

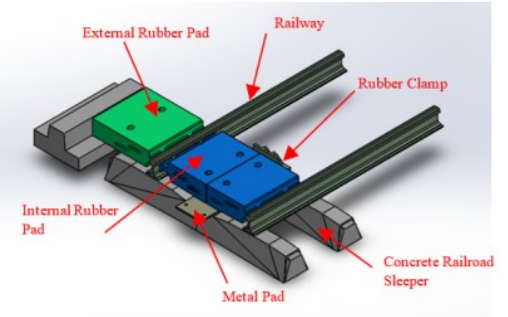

Fig. 2. Model components

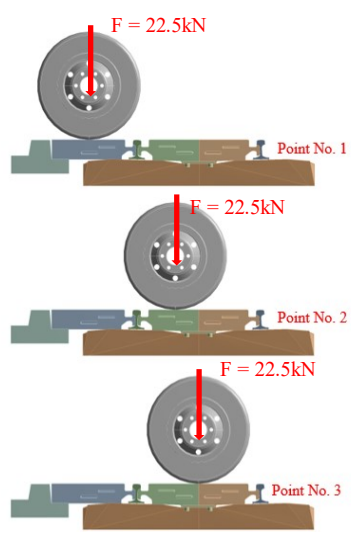

Fig. 3. Loading condition

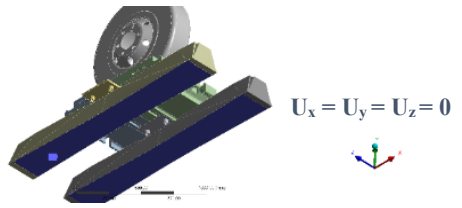

Fig. 4. Bottom fixed condition

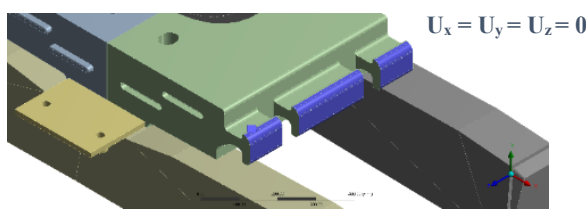

Fig. 5. Rubber panels fixed condition 
The contact relation between two internal rubbers are suppressed because the installation is done by inserting the two panels together without adhesive or fastener. The contact between rubber panels and metal pad was set as rough contact. For other contact relation set as bonded contact, they cannot separate from each other. The centre of contact between the two panels is wedge- shaped, which support assembly and allows the rubber to not separate from one another while the vehicle is passing. The wheel on this model is assumed to be a rigid body.

\subsection{Safety factor}

The rubber panels safety factor calculates by equation 2 .

$$
S F_{\text {Rubber }}=\frac{\text { Fracture strain (elongaton at break) }}{\text { Maximumequivalent strain }}
$$

The metal pad safety factor calculates by equation 3 .

$S F_{\text {Metal pad }}=\frac{\text { yiels stress of material }}{\text { Maximum von-mises stress }}$

The concrete safety factor calculates by equation 4 .

$S F_{\text {Concrete }}=\frac{\text { Ultimate tensile strenght }}{\text { Maximum priciple stress }}$

\section{Result and discussions}

The Finite Element Model with the boundary conditions is submitted in Ansys for Static Analysis. FEM model results of rubbers are obtained which include deflection. The simulation result in millimetre unit shown in figure 67 and 8 .

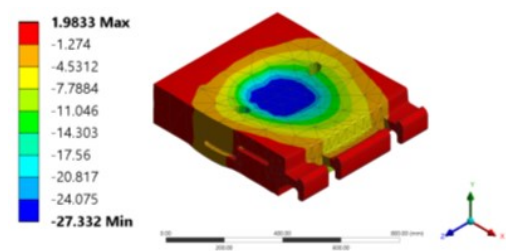

Fig. 6.Y axis deformation of External rubber point 1

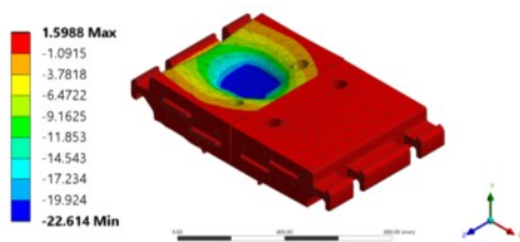

Fig. 7.Y axis deformation of Internal rubber point 2

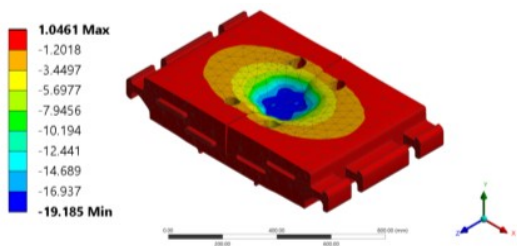

Fig. 8. Y axis deformation of Internal rubber point 3
The equivalent strain of external rubber panel shows as sample because this part is most deflated. Unit of equivalent strain is $\mathrm{mm} / \mathrm{mm}$.

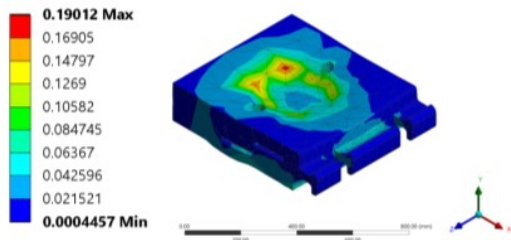

Fig.9. Maximum Equivalent Strain of External rubber point 1

When applying the force at each point, it was found that the centre of the external rubber panel had the greatest collapse. Cause this area is a wider than the internal rubber panel. To consider the internal rubber panel, the contact area between two rubber panels is less collapse than the centre of the rubber panel. Due to the metal pads under the rubber. If there are no metal pads, the collapse or separation of two rubber panels will increase. The collapse of the rubber panel occurs based on the accepted and can be restored to the original when the force removed. Because of the metal pad affects the deformation of the internal rubber panel, it must analyse the damage of the metal pads as well. The simulation result in millimetre unit shown in figure 10 and 11.

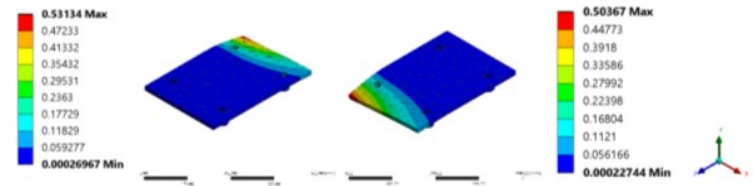

Fig. 10. Deformation of metal pad at point 2

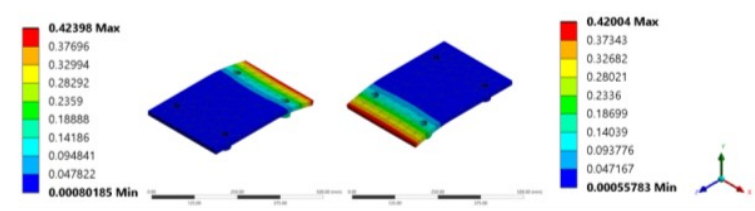

Fig. 11. Deformation of metal pad at point 3

Deformation and recovery of the metal pad can be determined from the highest stresses shown in figure 12 and 13 in MPa unit.

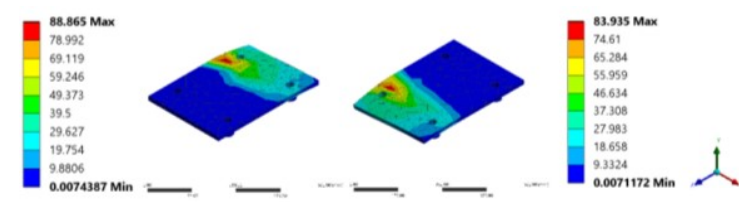

Fig. 12. Von-Mises Stress of metal pad at point 2

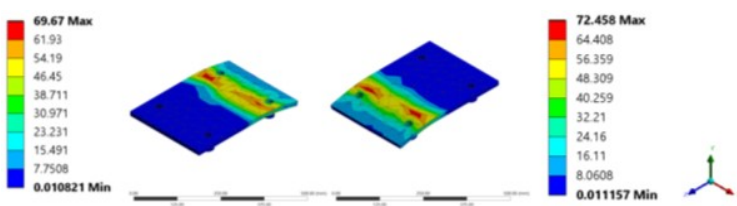

Fig. 13. Von-Mises Stress of metal pad at point 3 
Maximum stress that occurs in metal pad is $83.943 \mathrm{MPa}$ at point 2 loading. But the yield stress of this component is $250 \mathrm{MPa}$, according to mechanic properties of structural steel. That's metal pad just occurs elastic deformation and can be recovered to the initial shape. In case of the concrete railroad sleeper, it also has deformation from contact with metal pad. The deformation occurs very small section in millimeter unit but permanent. The most deformed area is loaded at point 1. Sample picture of the simulation results from loading on the external rubber panel shown below.
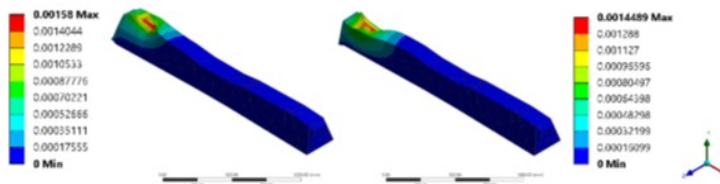

Fig. 14. Deformation of concrete railroad sleeper at point 1

For maximum principal stress of concrete railroad sleeper shown in figure 15 .
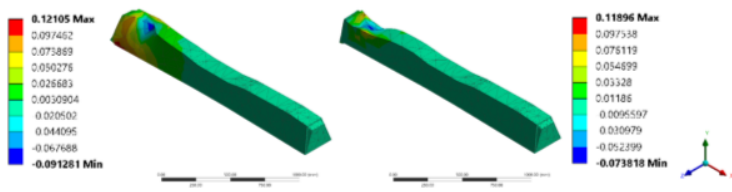

Fig. 15. Maximum principal stress of concrete railroad sleeper at point 1

According to FEM result can be following as shown in table 4 .

Table 4. Total of model

\begin{tabular}{|c|c|c|c|c|}
\hline Part & Result & $\begin{array}{l}\text { Load } \\
\text { point } 1\end{array}$ & $\begin{array}{c}\text { Load } \\
\text { point } 2\end{array}$ & $\begin{array}{c}\text { Load } \\
\text { point } 3\end{array}$ \\
\hline \multirow{2}{*}{ Rubber } & $\begin{array}{c}\mathrm{Y} \text { axis } \\
\text { deflection }(\mathrm{mm})\end{array}$ & 27.332 & 22.614 & 19.185 \\
\hline & $\begin{array}{c}\text { Maximum } \\
\text { equivalent strain } \\
\text { (MPA) }\end{array}$ & 0.19012 & 0.56379 & 0.33609 \\
\hline \multirow{4}{*}{ Metal pad } & \multirow{2}{*}{$\begin{array}{l}\text { Deformation } \\
\text { (mm) }\end{array}$} & - & 0.53134 & 0.42398 \\
\hline & & - & 0.50367 & 0.42004 \\
\hline & \multirow{2}{*}{$\begin{array}{c}\text { Von-Mises } \\
\text { Stress (Mpa) }\end{array}$} & - & 88.865 & 72.458 \\
\hline & & - & 83.935 & 69.67 \\
\hline \multirow{4}{*}{$\begin{array}{c}\text { Concrete } \\
\text { railroad } \\
\text { sleeper }\end{array}$} & \multirow{2}{*}{$\begin{array}{l}\text { Deformation } \\
\text { (mm) }\end{array}$} & 0.00145 & 0.00859 & 0.00711 \\
\hline & & 0.0158 & 0.00943 & 0.00739 \\
\hline & \multirow{2}{*}{$\begin{array}{c}\text { Principle } \\
\text { Stress (Mpa) }\end{array}$} & 0.11896 & 0.9767 & 1.1749 \\
\hline & & 0.12105 & 1.62 & 1.34 \\
\hline
\end{tabular}

From table 4 can use the maximum value to calculate safety factor.
Table 5. Safety factor of model

\begin{tabular}{|c|c|c|c|}
\hline Part & $\begin{array}{c}\text { Load } \\
\text { point 1 }\end{array}$ & $\begin{array}{c}\text { Load } \\
\text { point 2 }\end{array}$ & $\begin{array}{c}\text { Load } \\
\text { point 3 }\end{array}$ \\
\hline Rubber & 27.03 & 9.12 & 15.29 \\
\hline $\begin{array}{c}\text { Metal } \\
\text { pad }\end{array}$ & - & 2.81 & 3.45 \\
\hline $\begin{array}{c}\text { Concrete } \\
\text { railroad } \\
\text { sleeper }\end{array}$ & 41.31 & 3.09 & 3.73 \\
\hline
\end{tabular}

\section{Conclusions}

The rubber has suitable properties and can be used in real production the external rubber panel deflection is 27.332 $\mathrm{mm}$. For internal rubber panels maximum deflection is $22.614 \mathrm{~mm}$ from loading at point 2. Safety factor of external rubber panel is 27.03. Safety factor of internal rubber panels are 9.12 and 15.29. The deformation according to metal pads that support below rubber panels. Metal pads also deflection from load, but the deformation of metal pad occurs in elasticity period. The concrete railroad sleeper very small section. From the analysis result can be estimated that the model can be used.

\section{References}

[1] S. Kavin, Development of rail pads from chloroprene rubber and natural rubber blend, 110 (2005)

[2] O. Uwe, P. Martin, S. Eck, W. Daves, Validation of a finite element crossing model using measurements at an instrumented turnout (2013)

[3] K. Yuttakit, Manufacturing and testing concrete railway sleeper manual (2014)

[4] TIS 2667-2015, Rail way rubber standard (2015)

[5] ISO 37 international standard "Rubber, vulcanized or thermoplastic - Determination of tensile stress- strain properties" (2011)

[6] ISO 2285 international standard "Rubber, vulcanized or thermoplastic - Determination of tension set under constant elongation, and of tension set, elongation and creep under constant tensile load" (2013)

[7] ISO 7743 international standard "Rubber, vulcanized or thermoplastic - Determination of compression stressstrain properties" (2011)

[8] The state railway of Thailand, NSTDA, KMUTT, NRCT, The Knowledge Accumulation of Rail Transportation: Case Study of Infrastructure- Basic railway (2015)

[9] The state railway of Thailand, Specification for the supply of rubber solepad. (1982) 